\title{
Cavitation Erosion of NiTi Composite coating Deposited by Atmospheric Plasma Spraying
}

\author{
Dejia Zhu, Xinlong Wei", Chao Zhang* \\ College of Mechanical Engineering, Yangzhou University, Yangzhou 225127, China \\ *Corresponding Author: 18796603238@163.com, zhangc@yzu.edu.cn
}

\begin{abstract}
The surface properties and cavitation erosion performance of $\mathrm{NiTi} / \mathrm{NiCr}-75 \% \mathrm{Cr}_{3} \mathrm{C}_{2}$ composite coatings on AISI 304 stainless steel substance by atmospheric plasma spraying (APS) at different hydrogen gas flow rate were investigated. Composite coatings were characterized for microhardness. Microstructure of the cross section of composite coatings were investigated by scanning electron microscopy (SEM) with energy-dispersive X-ray spectroscopy (EDS). Caivation erosion test was finished by ultrasonic stretching vibration caviation test machine. The results show that when the hydrogen gas flow rate is $3 \mathrm{~L} / \mathrm{min}$ and $6 \mathrm{~L} / \mathrm{min}$, the microhardness of coatings are respectively $640 \mathrm{HV}$ and $730 \mathrm{HV}$ at a load of $100 \mathrm{~g}$ and a dwell time of 15 s condition, and the composite coatings by APS generates porosity and were oxidized. The cavitation erosion resistance of composite coatings is better than that of nodular cast iron. As the hydrogen gas flow rate increases, the microstructure of composite coating deposited by APS has lower porosity, and the better cavitation erosion resistance.
\end{abstract}

Keywords: cavitation erosion; $\mathrm{NiTi} / \mathrm{NiCr}-75 \% \mathrm{Cr}_{3} \mathrm{C}_{2}$ composite coatings; atmospheric plasma spraying.

\section{Introduction}

Cavitation erosion is caused by the internal pressure change of the liquid, which causes the dissolved gas in the liquid to nucleate, grow and collapse, and the cavitation collapse process will form a huge stress pulse, which will cause the surface damage of the material on the metal surface $^{(1)}$. Cavitation is widely present in various types of hydraulic machinery, such as the propellers of ship, the cylinder liner, which will lead to premature component failure and even major accidents, resulting in heavy economic losses ${ }^{(2,3)}$. Cavitation erosion is a complex process. Under certain special conditions, chemical corrosion, electrochemical corrosion and heat may interact with mechanical action to promote the occurrence of cavitation damage.

The NiTi alloys, which is famous for its excellent shape memory effect, has excellent super elasticity, wear resistance and cavitation erosion resistance. It is widely used in aviation, aerospace, machinery, transportation, chemistry, medical, energy and other fields ${ }^{(4,5)}$. However, the NiTi alloys are too expensive and have poor machinability ${ }^{(6)}$. Therefore, an feasible method to prevent cavitation damages is to deposit the surface with NiTi coatings, such as explosive welding ${ }^{(7)}$, cladding $^{(8)}$ and laser metal deposition ${ }^{(9)}$. Among all these techniques, atmospheric plasma spray (APS) belongs to the most promising technique ${ }^{(10)}$. APS has widely used in industry in recent years due to its advantages of high flame and powder particles velocity, and an inert gas such as $\mathrm{N}_{2}$ is used for spraying, with which a dense coating with superior bond strength, low oxide content could be prepared.

In the present, attention has been focused on development of metal/ceramic composite coatings due to its outstanding mechanical and multifunctional properties. Farvizi et al. added a low weight percentage of hard $\mathrm{Al}_{2} \mathrm{O}_{3}$ nanoparticles to NiTi atomized powders and reported that mechanical properties was considerably increased in the composite samples in comparison with pure NiTi, while the pseudoelasticity was not significantly reduced ${ }^{(11)}$. 
$\mathrm{NiCr}-\mathrm{Cr}_{3} \mathrm{C}_{2}$ composites ceramic coatings are widely used for surface strengthening of components due to high temperature resistance, wear resistance and corrosion resistance ${ }^{(12,13)}$. Huang et al. reported that the $\mathrm{Ni}$ based composite coatings have been obtained by using the plasma spray welding process and mixed powders $(\mathrm{NiCrBSi}+$ $\mathrm{NiCr}-\mathrm{Cr}_{3} \mathrm{C}_{2}+\mathrm{WC}$ )., exhibited enhance the coating hardness and good mechanical properties ${ }^{(14)}$.

Therefore, the aim of this research is to research the effect of APS parameters- hydrogen gas flow rate affect the coating architecture, mechanical properties and cavitation erosion resistance of $\mathrm{NiTi} / \mathrm{NiCr}-75 \% \mathrm{Cr}_{3} \mathrm{C}_{2}$ composite coatings in detail.

\section{Experimental procedure}

\subsection{Coating Preparation}

In the present study, the near equal atomic ratio pre-alloyed NiTi powders with spherical particles prepared by gas atomization were prepared as feedstock materials in the present study and particle size was $20 \sim 30 \mu \mathrm{m}$. $\mathrm{NiCr}-75 \% \mathrm{Cr}_{3} \mathrm{C}_{2}$ with size of $44 \sim 74 \mu \mathrm{m}$ was used as the reinforcement. And through mechanical mixing of NiTi and $\mathrm{NiCr}-75 \% \mathrm{Cr}_{3} \mathrm{C}_{2}$ powders by mass ratio $1: 1$.

This paper mainly studies the properties of the coatings, does not involve the substrate, for the convenience of experiment, select 304 stainless steel with dimensions of $60 \times 40 \times 6 \mathrm{~mm}$ as the substrate. The chemical composition of AISI 304 stainless steel was shown in Table 1. Prior to spraying: Substrate were grinded with 600grit silicon carbide (SiC) papers, and cleaned by alcohol. Next, the substrates were grit blasted by 24 mesh brown corundum to activate the surface.

Table 1. Chemical composition of AISI 304 stainless steel.

\begin{tabular}{|c|c|c|c|c|c|c|c|c|c|}
\hline Element & $\mathrm{C}$ & $\mathrm{Si}$ & $\mathrm{Mn}$ & $\mathrm{S}$ & $\mathrm{P}$ & $\mathrm{Cr}$ & $\mathrm{Ni}$ & $\mathrm{N}$ & $\mathrm{Fe}$ \\
\hline $\begin{array}{c}\text { Content } \\
\text { (wt. \%) }\end{array}$ & 0.046 & 0.51 & 1.06 & 0.004 & 0.025 & 18.32 & 8.04 & 0.05 & 71.945 \\
\hline
\end{tabular}

In this research, the coating deposition was carried out using an F4MB-XL plasma gun (Oerlikon Metco, Switzerland). A six-axis robot manipulator (ABB, Sweden) was used to get a uniform movement of the plasma gun. The optimized spraying parameters were given in Table 2 . $\mathrm{N}_{2}$ was used to create plasma, prevent unwanted reactions and transfer powders to APS gun. To reduce the substrate temperature, compressed air was placed at the reverse side of the substrates at a pressure of $0.3 \mathrm{MPa}$ as cooling gas. The as-sprayed coatings had a thickness of approximately $150 \mu \mathrm{m}$.

\subsection{Coating Characterization}

The cross-sectional morphologies of deposited coatings were observed by Supra 55 field emission scanning electron microscope (SEM) at an accelerating voltage of $20 \mathrm{kV}$.

The microhardness of the coatings was measured by using an HV-1000A hardness tester. Vickers indentation experiments were performed using a load of $100 \mathrm{~g}$ and a dwell time of $15 \mathrm{~s}$. Ten indentations on each coating were conducted and an average value was calculated.

Table 2. Selected plasma spraying parameters.

\begin{tabular}{|c|c|c|}
\hline Sample & APS-3 & APS-6 \\
\hline Plasma current $(\mathrm{A})$ & 51.5 & 51.5 \\
\hline Plasma voltage $(\mathrm{V})$ & 57 & 57 \\
\hline Primary gas, $\mathrm{N}_{2}(\mathrm{~L} / \mathrm{min})$ & 10 & 10 \\
\hline Secondary gas, $\mathrm{H}_{2}(\mathrm{~L} / \mathrm{min})$ & 3 & 6 \\
\hline Spraying distance $(\mathrm{mm})$ & 120 & 120 \\
\hline Powder feed rate $(\mathrm{g} / \mathrm{min})$ & 30 & 43 \\
\hline
\end{tabular}

\subsection{Cavitation Erosion Tests}

The NiTi/NiCr-75\% $\mathrm{Cr}_{3} \mathrm{C}_{2}$ coating specimens with the geometry of $16 \mathrm{~mm}$ diameter was machined as suitable for the cavitation tests and the specimens were investigated in as-sprayed conditions. The samples were tested at temperatures of $25{ }^{\circ} \mathrm{C}$ in the distilled water with an amplitude of $60 \sim 70 \mu \mathrm{m}$ and a frequency of $20 \mathrm{kHz}$. The gap between vibrating component and test surface was set equal to $0.2 \mathrm{~mm}$. Furthermore, the samples were ultrasonically cleaned in an ethanol bath for $10 \mathrm{~min}$. The mass loss was measured using an analytical balance with a precision of $0.1 \mathrm{mg}$.

In order to compare the cavitation resistance of the coatings with similar metal materials, nodular cast iron sample (QT500-7) was additionally tested. The chemical composition of nodular cast iron was shown in Table 3. 
Table 3. Chemical composition of nodular cast iron.

\begin{tabular}{|c|l|l|l|l|l|l|l|c|}
\hline Element & $\mathrm{C}$ & $\mathrm{Si}$ & $\mathrm{Mn}$ & $\mathrm{S}$ & $\mathrm{P}$ & $\mathrm{Mg}$ & $\mathrm{RE}$ & $\mathrm{Fe}$ \\
\hline Content (wt. \%) & 3.6 & 2.5 & 0.3 & 0.02 & 0.05 & 0.03 & 0.04 & Balance \\
\hline
\end{tabular}

\section{Results and Discussion}

\subsection{Microhardness of coatings}

Fig. 1 shows the measured microhardness values of the coatings. It should be noted that the hardness of the plasma spray coating is related to the hardness of the particles, the porosity and the adhesion. It is seen that APS-6 has the maximum hardness and the hardness of the coatings were much greater than that of nodular cast iron. Increasing the hydrogen gas flow rate will slightly increase the hardness of the coating. This is mainly because the powder melts more completely and the kinetic energy of powder particles increases as the hydrogen flow rate increases.

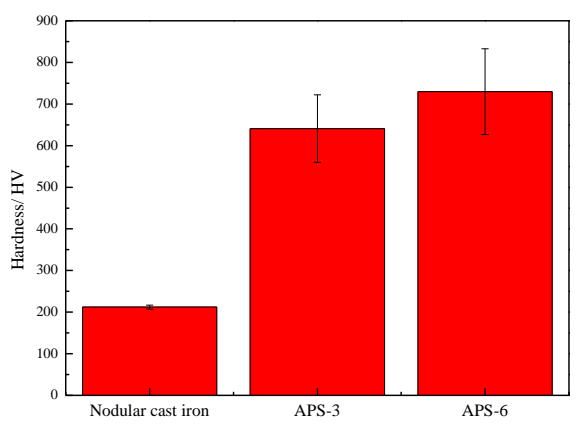

Fig. 1. Microhardness values of the coatings.

\subsection{Microstructure of coatings}

The cross section microstructure of coatings by APS are presented in Fig. 2. It can be seen that light-colored areas and dark areas where the coatings are alternately distributed, and some of the pores are present, and the microstructure of APS-6 coating is denser than that of APS-3 coating. Fig. 3 and Fig. 4 show the EDS mapping images of the cross section of coatings. The EDS mapping indicates that the $\mathrm{O}$ element appears in the coating and is uniform distribution. And the two powders are not completely mixed, the Ti elements are mainly distributed in the dark areas, and the $\mathrm{Cr}$ elements are distributed in the dark areas.
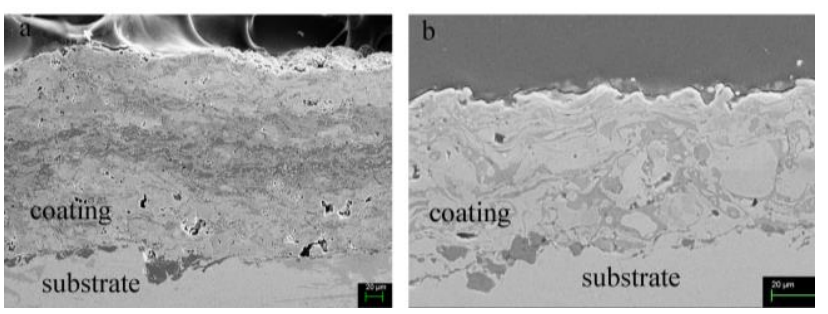

Fig. 2. Microstructure of the cross section of coatings produced by APS (a) APS-3, (b) APS-6.
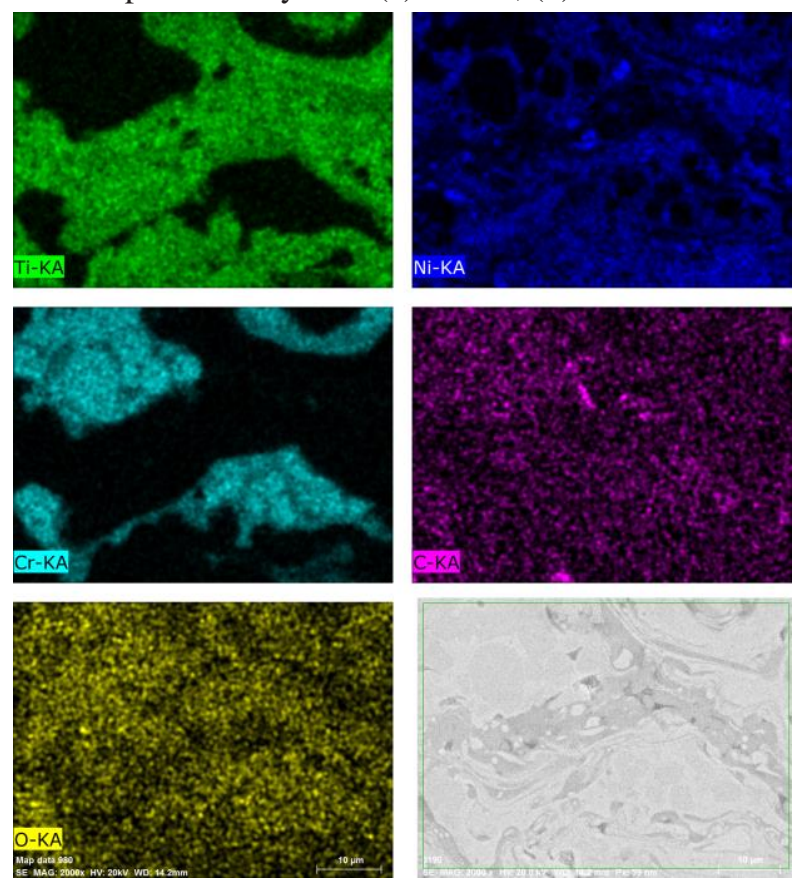

Fig. 3. EDS spectrum and elemental mapping images of the cross section of APS-3.
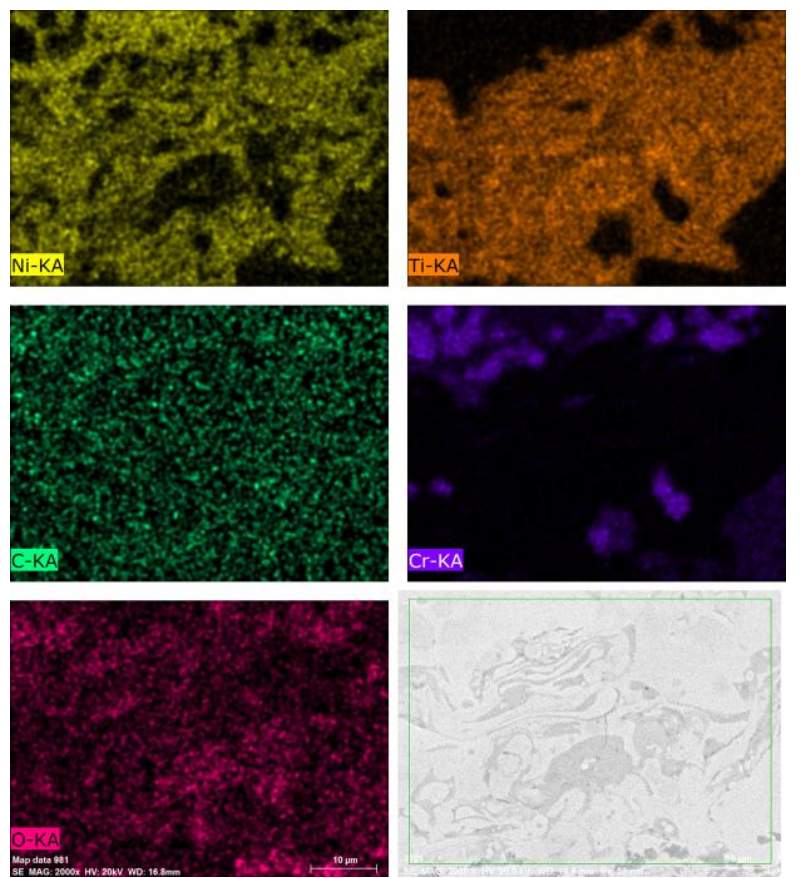

Fig. 4. EDS spectrum and elemental mapping images of the cross section of APS-6. 


\subsection{Testing results of cavitation erosion test}

Cavitation erosion curves of samples are shown in Fig. 5. It can be seen that the mass loss of nodular cast iron is the most serious, and the cumulative amount is $13.2 \mathrm{mg}$. This is mainly because nodular cast iron has the lowest hardness. APS-3 coating and APS-6 coating have similar mass loss changes, and APS- 6 coating has the least mass loss. This is consistent with the previous conclusion because porosity on the surface of the coating and low hardness accelerate the onset of erosion under cavitation conditions $^{(15)}$.

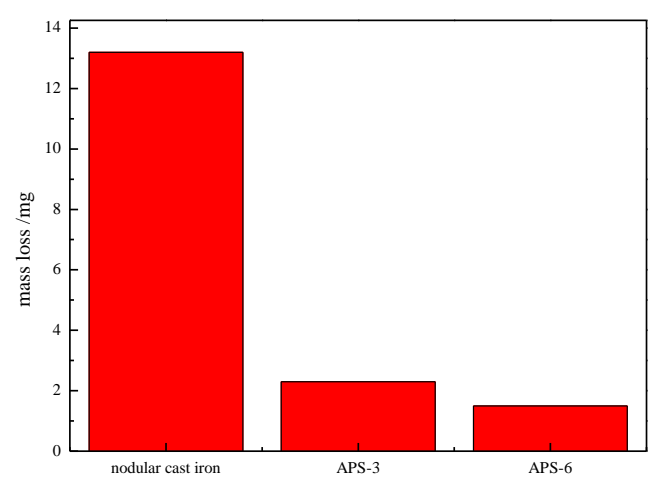

Fig. 5. Mass loss as a function of the cavitation exposure time for the evaluated samples.

\section{Conclusions}

$\mathrm{NiTi} / \mathrm{NiCr}-75 \% \mathrm{Cr}_{3} \mathrm{C}_{2}$ Composite coatings were deposited at different hydrogen gas flow rate by APS. The microhardness, characterization and cavitation erosion of the coatings were investigated. Following conclusions can be drawn:

1) The microhardness of APS-3 and APS-6 coatings were respectively $640 \mathrm{HV}_{0.1}$ and $730 \mathrm{HV}_{0.1}$.

2) Increasing the hydrogen gas flow rate, the coating deposited by APS has denser and lower porosity microstructure.

4) After $9 \mathrm{~h}$ of cavitation, the cumulative cavitation of APS- 6 coating was $1.5 \mathrm{mg}$, and the accumulated cavitation of nodular cast iron was $13.2 \mathrm{mg}$. The cavitation resistance of the coatings were better than that of nodular cast iron.

\section{References}

(1) ChristopherEarls Brennen : "Cavitation and bubble dynamics", Oxford University press, 1995
(2) YoungZehr Keir, and JuiHsiang Kao : "Underwater acoustic field and pressure fluctuation on ship hull due to unsteady propeller sheet cavitation", Journal of Marine Science and Technology, Vol. 16, No. 3, pp. 241-253, 2011

(3) Fontanesi Stefano, Giacopini Matteo, Cicalese Giuseppe, Simone Sissa, and Stefano Fantoni : "Numerical investigation of the cavitation damage in the wet cylinder liner of a high performance motorbike engine", Engineering Failure Analysis, Vol. 44, pp. 408-423, 2014

(4) Hitoshi Hiraga, Takashi Inoue, Hirofumi Shimura, and Akira Matsunawa : "Cavitation erosion mechanism of NiTi coating made by laser plasma hybrid spraying", Wear, Vol. 231, No. 7, pp. 272-278, 1999

(5) Song Zhang, Chunhua Zhang, Hauchung Man, and Changsheng Liu : "Laser surface alloying fabricated porous coating on NiTi shape memory alloy", Transactions of Nonferrous Metals Society of China, Vol. 17, No. 2, pp. 228-231, 2007

(6) Yifeng Hu, Wen Deng, and Zhenying Chen : "Study on electronic structure and microdefects by positron annihilation spectroscopy for NiTi alloys", Rare Metal Materials and Engineering, Vol. 36, No. 6, pp. 985-988, 2007

(7) Zhu Yan, Lishan Cui, and Yanjun Meng : "Microstructure and martensitic transformation behaviors of explosively welded NiTi/NiTi laminates", Chinese Journal of Aeronautics, Vol. 20, No. 2, pp. 168-171, 2007

(8) Fencheng Liu, Yuqing Mao, Xin Lin, Baosheng Zhou, and Tao Qian : "Microstructure and high temperature oxidation resistance of $\mathrm{Ti}-\mathrm{Ni}$ gradient coating on $\mathrm{TA}_{2}$ titanium alloy fabricated by laser cladding", Optics \& Laser Technology, Vol. 83, pp. 140-147, 2016

(9) MokgadiNomsa Mokgalaka, SisaLesley Pityana, PatriciaAbimbolaIdowu Popoola, and Tebogo Mathebula : "NiTi intermetallic surface coatings by laser metal deposition for improving wear properties of Ti-6Al-4V substrates", Advances Materials Science and Engineering, Vol. 2014, No. 2014, pp. 8, 363917, 2014

(10) Bitzer Martin, Rauhut Nadine, Mauer Georg, Martin Bram, Robert Vassen, Hans-Peter Buchkremer, Detlev 
Stoever, and Michael Pohl : “Cavitation-resistant NiTi coatings produced by low-pressure plasma spraying (LPPS)", Wear, Vol.328, pp. 369-377, 2015

(11) Mohammad Farvizi, Touradj Ebadzadeh, MohammadReza Vaezi, Hee-Sun Kim, and Abdolreza Simchi : "Effect of nano $\mathrm{Al}_{2} \mathrm{O}_{3}$ addition on mechanical properties and wear behavior of NiTi intermetallic", Materials \& Design, Vol. 51, pp. 375-382, 2013

(12)Zhaoqian Xie, Huayuan Huan, Fei Liu, Yuqiang Zhao, and Haijun Wang : "Study on High Temperature Performances of $\mathrm{NiCr}-\mathrm{Cr}_{3} \mathrm{C}_{2}$ Coatings by Supersonic Plasma Spraying”, Rare Metal Materials and Engineering, Vol. 41, pp. 726-730, 2012

(13) Chuncheng Zang, Yanzhong Wang, Yidu Zhang, Jinhua Li, Hong Zeng, and Deqiang Zhang : "Microstructure and wear-resistant properties of $\mathrm{NiCr}-\mathrm{Cr}_{3} \mathrm{C}_{2}$ coating with $\mathrm{Ni45}$ transition layer produced by laser cladding”, Rare Metals, Technology, No. 34, Vol. 7, pp. 491-497, 2015

(14) Shiming Huang, Daqian Sun, and Wenquan Wang : "Microstructures and properties of Ni based composite coatings prepared by plasma spray welding with mixed powders", International Journal of Refractory Metals \& Hard Materials, Vol. 52, pp. 36-43, 2015

(15) Hiromi Mochizuki, Motohiro Yokotab, and Shuji Hattori : "Effect of materials and solution temperatures on cavitation erosion of pure titanium and titanium alloy in seawater", Wear, Vol. 262, No. 5-6, pp. 522528,200 